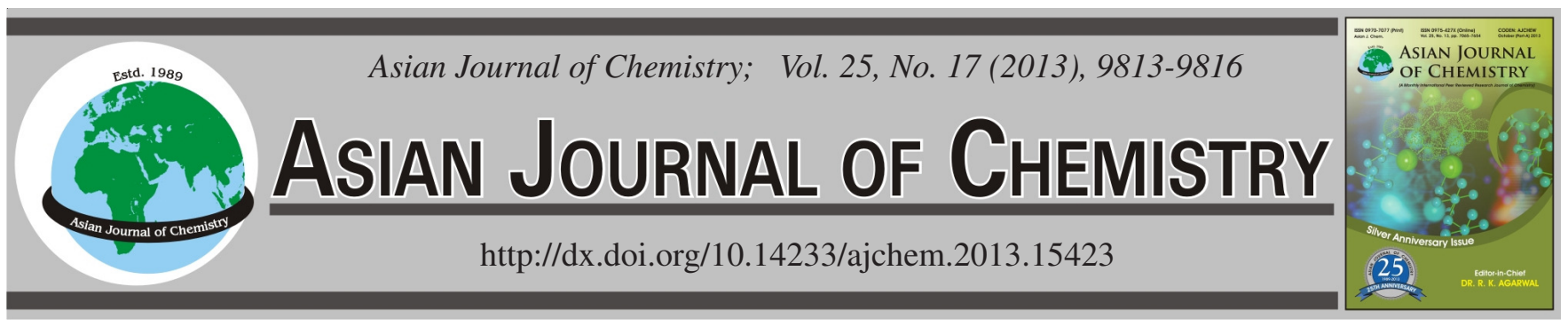

\title{
Physico-chemical and Geochemical Correlation Study of Aliphatic Hydrocarbons for Sindh Basin (Pakistan) Condensate Samples
}

\author{
M.A. ZulfiQAR ${ }^{1}$, M. ZAhiD ${ }^{2, *}$ and T. FAZEELAT ${ }^{1, *}$
}

${ }^{1}$ Department of Chemistry, University of Engineering and Technology, Lahore, Pakistan

${ }^{2}$ Department of Chemistry \& Biochemistry, University of Agriculture, Faisalabad, Pakistan

*Corresponding authors: Tel: +92 41 9200161; Ext. 3309, E-mail: rmzahid@uaf.edu.pk; fazeelat.tahira@gmail.com

(Received: 5 March 2013;

Accepted: 23 October 2013)

AJC-14281

\begin{abstract}
Various condensate samples (Ali-1, Bilal-1, Bilal North-1 and Naimat Basal-1) are obtained from Lower Goru formation (Cretaceous) of Sindh basin (Pakistan). A molecular study for saturated/aliphatic hydrocarbons, isolated from these samples, is carried out in order to investigate genetic relationship among the samples. Moreover, physico-chemical analyses are also carried out by using ASTM methods. All the condensates show almost similar physico-chemical characteristics. These samples also show close resemblance in terms of molecular parameters. Therefore, they are suggested to share similar source. Some observed variations in physico-chemical and geochemical properties for Ali-1 compared to other condensate samples are interpreted in terms of maturity difference.
\end{abstract}

Key Words: Physico-chemical properties, Aliphatic hydrocarbon, Sindh basin (Pakistan).

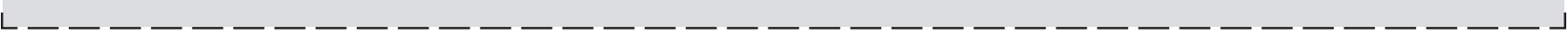

\section{INTRODUCTION}

The analysis involves the bulk parameters of the condensates, GC-FID analysis of the saturated or aliphatic hydrocarbons in the samples and their genetic correlation by using different methodologies. Bulk properties regarding condensates and crude oils are useful for primary screening and to an extent depict identification of all genetically related condensates and oils. These properties reflect a relative amount of different classes of chemical compounds in the condensate. Geological processes like reservoir temperature, water washing, maturation, biodegradation, depositional environment etc., change their composition, so the physical and chemical characteristics vary from one another.

To establish valid oil-oil correlations, parameters have to be chosen that are not changed by maturation or secondary alteration processes ${ }^{1}$. Geochemical fossils or biomarkers provide one of the best correlation tools. Biomarker compounds are widely used in organic geochemistry for oil-oil and oilsource rock correlation, as depositional environment indicators as well as indicators of thermal history or maturation of petroleum. Biomarkers are molecules in crude oils, source rocks and sediments whose carbon skeleton can be traced back to living organisms. They are microfossils generally specific for an organism and are highly variable in their stereochemistry, that is, the spatial arrangement of atoms and groups in their molecules. Because of this variability, fossil biomarkers frequently can be linked directly to the specific group of plants, animals or bacteria from which they originated ${ }^{2}$. Although individual biomarkers are in concentrations of only 10-200 ppm in crude oils, they can be accurately measured inspite of their unusual complexity and variety which find their use in source rock correlation and maturation studies. Correlations using chemical fossil technology can be applied in real cases by recognizing the gas chromatogram (GC) of the hydrocarbon molecules in the oils to know whether they have the same biomarkers or similar geohistory of origin and migration. Thus, a biomarker compound in a particular source rock would be expected to appear in the oils it generated ${ }^{3}$.

The parameters suitable for correlations can be chosen from various classes of hydrocarbons and non-hydrocarbons normally present in crude oils. Further, in oil-oil correlation, it is advisable to select parameters in such a way that a wide molecular weight range is covered for any given correlation parameter. Such information can be provided, for instance, by the $n$-alkane distribution curve or by the gas chromatography record of the saturated hydrocarbon fraction on a capillary column ${ }^{4}$. A study for source assessment based on the geochemical characterization of organic matter and maturity of the crude oil samples obtained from Lower Indus Basin, Pakistan has indicated two different origins; one contains majorly aquatic source of organic matter and the other has significant share of land plant organic matter 5 . 


\section{EXPERIMENTAL}

In the present study, four condensate samples from Lower Goru formation (Cretaceous) of Sindh basin are used. These samples were provided by Orient Petroleum International Inc. (OPII). Some general and geological data of these condensate samples are given in Table-1.

\begin{tabular}{lccc}
\multicolumn{4}{c}{ TABLE-1 } \\
\multicolumn{4}{c}{$\begin{array}{c}\text { GENERAL AND GEOLOGICAL } \\
\text { DATA OF CONDENSATE SAMPLES }\end{array}$} \\
\hline \multirow{2}{*}{ Name of well } & $\begin{array}{c}\text { Depth } \\
(\mathrm{ft})\end{array}$ & $\begin{array}{c}\text { Reservoir } \\
\text { temp. }\left({ }^{\circ} \mathrm{F}\right)\end{array}$ & $\begin{array}{c}\text { Operating } \\
\text { company }\end{array}$ \\
\hline Ali-1 & 10844 & 577.4 & OPII \\
Bilal-1 & 10204 & 548.6 & OPII \\
Bilal North-1 & 10200 & 536 & OPII \\
Naimat basal-1 & 11590 & 573.8 & OPII \\
\hline
\end{tabular}

The Goru formation is dominantly shale or mudstone, frequently calcareous. It is thin bedded where bedding is discernible and ranges in colour from black to grey and locally maroon. Sand is rare in the upper part with increasing tendency towards base where it has developed into a producing reservoir. Only locally does limestone form a significant percentage of the formation. On the basis of its lithological content, it has been divided into Lower Goru and Upper Goru. The name Lower Goru has been applied to the lower sandy member whereas within the same area, the upper shale unit is termed as Upper Goru. Environment appears to have been generally marine with relatively deep water as indicated by the generally pelagic fauna. Moreover, the petroleum potential of Lower Goru sand is very good as it contains all the hydrocarbons in Sindh monocline ${ }^{6}$.

Bulk properties of condensate samples were determined by using different techniques according to ASTM methods and results are shown in Table-2. For geochemical analysis, condensate samples were desulphurized by passing them through precipitated copper powder in a column ${ }^{7}$. These desulphurized condensates were fractionated into saturates, aromatics, resins and NSO (nitrogen, sulphur and oxygen compounds) and asphaltenes by column chromatography on silica gel. A glass column $(40 \mathrm{~cm} \times 1.2 \mathrm{~cm}$ i.d. $)$ was packed with a slurry of $5 \mathrm{~g}$ freshly activated silica $\left(105^{\circ} \mathrm{C}\right.$ for $\left.24 \mathrm{~h}\right)$ in $n$-hexane $(20 \mathrm{~mL})$. The condensate $(50 \mathrm{mg})$ in $n$-hexane was introduced onto the column. The saturates were separated by elution with three bed volumes of $n$-hexane, the aromatics with three bed volumes of 95:5n-hexane: diethyl ether, resins/NSO compounds with three bed volumes of methanol and finally asphaltenes with three bed volumes of chloroform. The fractions were evaporated to dryness and results are shown in Table-3. Saturated hydrocarbon fraction of each condensate sample was analyzed by GC-FID.

Saturated hydrocarbon fractions were analyzed by gas chromatography, using Shimadzu 14-B series (Japan) gas chromatograph, equipped with Flame Ionization Detector (FID) and fused silica capillary column $(30 \mathrm{~m} \times 0.25 \mathrm{~mm}$ i.d. $)$, coated with methyl silicon (OV-1) $0.25 \mu \mathrm{m}$ film thickness. The concentrations of sample (saturated fraction) and internal standard (fluorene) were: $10 \mathrm{mg} / 1 \mathrm{~mL}$ and $1 \mathrm{mg} / 3 \mathrm{~mL}$ respectively, cyclohexane was used as solvent. The sample and internal standard (IS) were mixed in the ratio 80:20 and $1 \mu \mathrm{L}$ was injected into the GC column in a splitless mode. The GC operating conditions were: 60(1)@ $4{ }^{\circ} \mathrm{C} / \mathrm{min}-280(5)$. Injector and detector (FID) temperatures were 250 and $280{ }^{\circ} \mathrm{C}$ respectively. Nitrogen at a linear velocity of $2 \mathrm{~mL} / \mathrm{min}$ was used as a carrier gas. The data was collected for retention time 0-65 min.

\section{RESULTS AND DISCUSSION}

Bulk properties: Bulk properties of the condensate samples were determined by physico-chemical parameters and are shown in Table-2. These properties are routinely used to characterize crude oils and condensate samples.

Low values of specific gravity $(0.77-0.78)$ have been observed which indicates more abundance/concentration of light hydrocarbons. API gravity of analyzed condensate samples lie in the range 47.7-51.6. These values are typical of light and commercially valuable oils.

Reid vapour pressure (RVP) and kinematic viscosity values range from 3.5 to 6.4 and 1.02 to 1.10 , respectively. This shows that Bilal North-1 is lighter than others due to the high percentage of low molecular weight hydrocarbons because of synthesis of smaller molecules and cracking of larger molecules so this is more mature while Ali-1 shows little bit greater values as compared to others due to vice versa properties.

Sulphur contents are the major source of corrosion and plant rusting. The amount of sulphur in condensates is important in terms of their handling within the refinery and its undesirable effects in finished products. Sulphur contents in these condensates are very low having values $0.06-0.07$ with copper strip corrosion test 1a, so these will not corrode storage tanks easily and thus are easy to handle and commercially more important.

Geochemical study: The relative percentage of saturates, aromatics, resins/NSO compounds and asphaltenes in condensates obtained by column chromatography is shown in Table- 3 . All the samples analyzed in this study contain more than $50 \%$

TABLE-2

BULK PROPERTIES OF CONDENSATES FROM SINDH BASIN

\begin{tabular}{lcccc}
\hline \multicolumn{1}{c}{ Bulk properties } & Ali-1 & Bilal-1 & Bilal north-1 & Naimat basal-1 \\
\hline Appearance & Transparent & Transparent & Transparent & Transparent \\
Colour (visual) & Yellowish green & Light brown & Light greenish yellow & Light greenish \\
Specific gravity $\left(60 / 60{ }^{\circ} \mathrm{F}\right)$ & 0.790 & 0.782 & 0.773 & 0.780 \\
API Gravity $\left(60 / 60^{\circ} \mathrm{F}\right)$ & 47.7 & 49.4 & 51.6 & 50.0 \\
RVP at $37.8^{\circ} \mathrm{C}(\mathrm{Psi})$ & 3.5 & 4.7 & 6.4 & 4.7 \\
Kinematic viscosity at $40^{\circ} \mathrm{C}(\mathrm{cSt})$ & 1.10 & 1.04 & 1.02 & 1.04 \\
Sulphur contents $(\mathrm{Wt} . \%)$ & 0.07 & 0.06 & 0.06 & 0.06 \\
Copper strip corrosion & $1 \mathrm{a}$ & $1 \mathrm{a}$ & $1 \mathrm{a}$ & $1 \mathrm{a}$ \\
\hline
\end{tabular}




\begin{tabular}{lcccc}
\hline \multicolumn{5}{c}{ TABLE-3 } \\
\multicolumn{5}{c}{ RELATIVE PERCENTAGE OF } \\
COMPOUND CLASSES IN CONDENSATES \\
\hline \multicolumn{1}{c}{ Condensates } & Saturates & Aromatics & Resins/NSOs & Asphaltenes \\
\hline Ali-1 & 60.5 & 10.1 & 28.8 & 0.6 \\
Bilal-1 & 79.2 & 4.6 & 15.8 & 0.4 \\
Bilal north-1 & 81.5 & 6.8 & 11.4 & 0.3 \\
Naimat basal-1 & 78.3 & 6.6 & 14.7 & 0.4 \\
\hline
\end{tabular}

saturates. According to Tissot and Welte ${ }^{4}$, crude oils containing more than $50 \%$ saturated hydrocarbons are classified as paraffinic oils. Therefore, all analyzed condensates are considered as paraffinic. As saturated hydrocarbons increase with maturity, thus Bilal North-1 is comparatively more mature than Ali-1.

The relative contributions of the suite of different $n$ alkanes included in the total hydrocarbon fractions provide information about the sources. For example, the large abundance of $\mathrm{C}_{27}, \mathrm{C}_{29}$ and $\mathrm{C}_{31} n$-alkanes in sediment extracts and crude oils show significant contribution from the land plants. While the profusion of $n-C_{17}$, in contrast, indicates the algal contributions $^{8}$. Therefore, terrestrial to aquatic ratio (TAR) values can be used in order to determine the source input of the crude oils and are calculated using eqn. 1. The sum of $n$-alkanes concentrations $\left(\mathrm{C}_{27}+\mathrm{C}_{29}+\mathrm{C}_{31}\right)$ can be used as a measure of the input of $n$-alkanes from terrestrial plants and the sum of $\left(\mathrm{C}_{15}+\mathrm{C}_{17}+\mathrm{C}_{19}\right)$ indicates $n$-alkanes from aquatic sources. When aquatic sources predominate, the terrestrial to aquatic ratio decreases to values ${ }^{9}$ less than 1.0.

$$
\text { TAR }=\frac{\mathrm{n}-\mathrm{C}_{27}+\mathrm{n}-\mathrm{C}_{29}+\mathrm{n}-\mathrm{C}_{31}}{\mathrm{n}-\mathrm{C}_{15}+\mathrm{n}-\mathrm{C}_{17}+\mathrm{n}-\mathrm{C}_{19}}
$$

Table-4 shows that the TAR values lie in the range 0.12 0.47 , so all samples have predominance of aquatic sources along with the contribution from terrestrial organic matter. The TAR values show that Bilal-1 and Naimat Basal-1 with TAR value 0.12 have more contributions of aquatic sources as compared to other condensate samples. The nature of the organic matter and the redox potential of the depositional environment of the oils and condensates can be determined by using $\mathrm{Pr} / \mathrm{Ph}$ ratio. This ratio is similar for petroleum, which has resulted from material deposited under similar conditions. The $\mathrm{Pr} / \mathrm{Ph}$ ratio of Bilal-1, Bilal North-1 and Naimat Basal-1 are greater than 3.0, so the organic matter was exposed to oxidation before or during deposition. Moreover, the more organic lean lacustrine, fluvial and deltaic sediments generate oils and condensate with ratios greater than 3.0. The $\mathrm{Pr} / \mathrm{Ph}$ ratio value for Ali-1 condensate is less than 3.0, it could be due to low comparative maturity.

Isoprenoid and $n$-alkane data provides valuable information on biodegradation, maturity and diagenetic conditions.
With increasing maturity, the $n$-alkanes are generated faster than isoprenoids resulting in a decrease in isoprenoid $/ n$ alkane ratios. Biodegradation, in contrast, removes $n$-alkanes faster, increasing isoprenoid $/ n$-alkane ratios ${ }^{10}$. Therefore, $\mathrm{Pr} /$ $n-\mathrm{C}_{17}$ and $\mathrm{Ph} / n-\mathrm{C}_{18}$ ratios greater than 1.0 shows biodegradation and this value less than 1.0 is an indication of non-biodegraded oil. The isoprenoid $/ n$-alkane ratio for these condensate samples is less than 1.0, so these samples are mature and non-biodegraded. There is the influence of source on these ratios, e.g., oil from source rock deposited under open water conditions show $\mathrm{Pr} / n-\mathrm{C}_{17}<0.5$, while those from peat swamp have ratios $>1.0^{11}$. The $\mathrm{Pr} / n-\mathrm{C}_{17}$ ratio lie in the range of $0.22-0.30$ as shown in Table-4. So these condensates were derived from source rocks deposited under open water conditions as this ratio is less than 0.5 .

Because of the limitations of the isoprenoid/ $n$-alkane ratios for correlation purposes due to its decrease with thermal maturity, a new ratio $\mathrm{Pr}+n-\mathrm{C}_{17} / \mathrm{Ph}+n-\mathrm{C}_{18}$ is proposed by Alexander et $a l .{ }^{12}$. The ratio should reflect more closely the nature of the kerogen, rather than the stage of generation reached in source rocks by reducing the effect of different proportions of $n$-alkanes and isoprenoids being produced at various stages of generation. Therefore, it appeared to be much more dependent on the nature of the source material and its depositional environment ${ }^{12}$. $\mathrm{Pr}+n-\mathrm{C}_{17} / \mathrm{Ph}+n-\mathrm{C}_{18}$ ratios for Bilal-1, Bilal North-1 and Naimat Basal-1 are nearly equal showing similar source material and depositional environment but Ali-1 is somewhat different from them.

The pre-dominance of odd versus even carbon numbered $n$-alkanes can be used to obtain a crude oil estimate of thermal maturity of petroleum. These measurements include the carbon preference index (CPI) and the improved odd even preference (OEP). The CPI and OEP values are calculated using eqns. 2 and 3 , respectively.

$$
\begin{gathered}
\mathrm{CPI}=\frac{1}{2}\left[\frac{\mathrm{C}_{23}+\mathrm{C}_{25}+\mathrm{C}_{27}+\mathrm{C}_{29}+\mathrm{C}_{31}}{\mathrm{C}_{24}+\mathrm{C}_{26}+\mathrm{C}_{28}+\mathrm{C}_{30}+\mathrm{C}_{32}}\right. \\
\left.+\frac{\mathrm{C}_{25}+\mathrm{C}_{27}+\mathrm{C}_{29}+\mathrm{C}_{31}+\mathrm{C}_{33}}{\mathrm{C}_{24}+\mathrm{C}_{26}+\mathrm{C}_{28}+\mathrm{C}_{30}+\mathrm{C}_{32}}\right] \\
\mathrm{OEP}=\frac{\mathrm{C}_{25}+6 \mathrm{C}_{27}+\mathrm{C}_{29}}{4 \mathrm{C}_{26}+4 \mathrm{C}_{28}}
\end{gathered}
$$

Odd carbon numbered $n$-alkanes are often formed in preference to the even carbon numbered compounds when petroleum forms from kerogen ${ }^{13}$. Thermal degradation of kerogen during catagenesis subsequently generates new alkanes without predominance. Thus, the preference of odd numbered molecules progressively disappears. These are maturity indi-

\begin{tabular}{|c|c|c|c|c|c|c|c|}
\hline Condensate samples & TAR & $\mathrm{Pr} / \mathrm{Ph}$ & $\mathrm{Pr} / n-\mathrm{C}_{17}$ & $\mathrm{Ph} / n-\mathrm{C}_{18}$ & $\frac{\mathrm{Pr}+\mathrm{n}-\mathrm{C}_{17}}{\mathrm{Ph}+\mathrm{n}-\mathrm{C}_{18}}$ & CPI & OEP \\
\hline Ali-1 & 0.47 & 2.90 & 0.22 & 0.07 & 1.05 & 1.04 & 1.07 \\
\hline Bilal-1 & 0.12 & 5.23 & 0.30 & 0.07 & 1.48 & 1.04 & 1.06 \\
\hline Bilal north-1 & 0.14 & 4.20 & 0.26 & 0.07 & 1.33 & 1.04 & 1.08 \\
\hline Naimat basal-1 & 0.12 & 4.46 & 0.28 & 0.07 & 1.33 & 1.06 & 1.09 \\
\hline
\end{tabular}
cator parameters for correlation between samples of similar

TABLE-4

TAR, Pr/Ph, ISOPRENOID/n-ALKANE RATIOS, CPI AND OEP OF CONDENSATE SAMPLES 
maturity. Their values significantly above (odd preference) or below (even preference) 1.0 indicate that the oil or extract is thermally immature. CPI and OEP values for the range $\mathrm{C}_{25}-\mathrm{C}_{29}$ are 1.04-1.06 and 1.06-1.09, respectively. As these values are very close to 1.0 , so these condensate samples are thermally mature.

Gas chromatograms (Fig. 1) show full suite of $n$-alkanes in saturate hydrocarbon fraction of condensates, which reveal that all samples analyzed in this study are non-biodegraded. Absolute concentrations of $n$-alkanes in the region $n-\mathrm{C}_{13}$ to $n-\mathrm{C}_{35}$ are calculated using eqn. 4 and are shown in Fig. 2 . These values have been calculated from GC peak area of desired the component (Fig. 1) by using the formula:

$$
\text { Absolute conc } .(n g)=\frac{\text { Conc. } \text { of IS }(n g) \times \text { Peak area }}{\text { Peak area of IS }}
$$

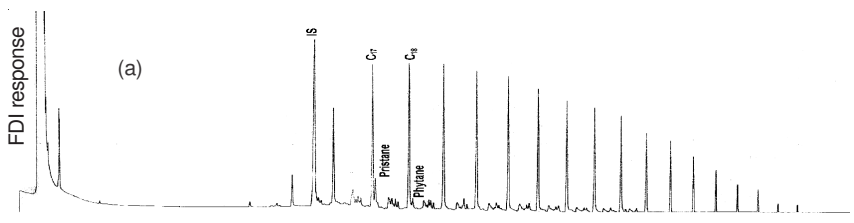

2468101214161820222426283032343638404244464850525456586062 Retention time (min)
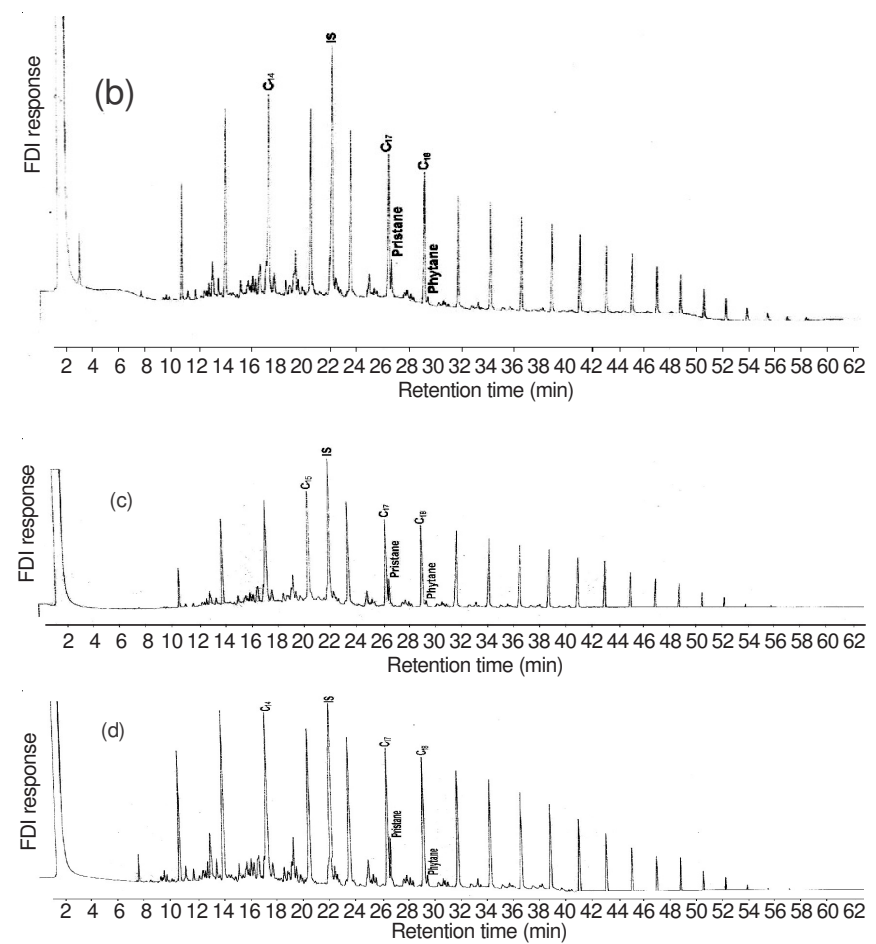

Fig. 1. Capillary gas chromatograms of saturate fraction of condensates of (a) Ali-1 (b) Bilal-1 (c) Bilal North-1 and (d) Naimat Basal-1

Absolute concentrations show that most abundant $n$ alkanes for these condensates lie between $\mathrm{C}_{14}-\mathrm{C}_{19}$, so these have algal source input ${ }^{14}$.

\section{Conclusion}

Following conclusions are drawn from this study: Bulk properties show that condensate samples are light with very low sulphur contents. The results from column chromatography

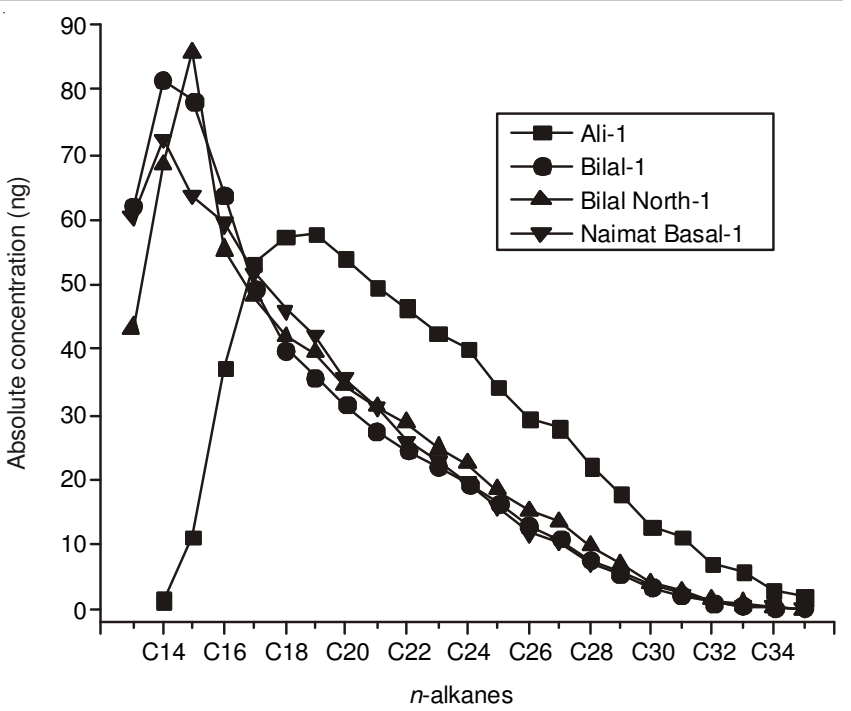

Fig. 2. Absolute concentrations of $n$-alkanes from $n$-C13 to $n$-C35 in condensate samples

show that these condensates are paraffinic. $\mathrm{Pr} / \mathrm{Ph}$ ratio show that these condensates were generated from sediment deposited under oxic environment. TAR values reveal that these condensates are predominantly derived from aquatic organic matter. CPI and OEP values show that these samples are thermally mature. Low isoprenoid $/ n$-alkane ratios and presence of full suit of $n$-alkanes in GC show that all samples analyzed in this study are nonbiodegraded. $\mathrm{Pr}+n-\mathrm{C}_{17} / \mathrm{Ph}+n-\mathrm{C}_{18}$ ratio reveal that Bilal-1, Bilal North-1 and Naimat Basal-1 condensates show similar source.

\section{ACKNOWLEDGEMENTS}

One of the authors (AZ) thank for Orient Petroleum, International Inc. (OPII) for samples. Thanks are due to M. Asif, A. Saleem and S. Nadeem for useful discussions.

\section{REFERENCES}

1. H. Justwan, B. Dahl and G.H. Isaksen, Mar. Petrol. Geol., 23, 213 (2006).

2. J.M. Hunt, Petroleum Geochemistry and Geology, Freeman, New York, edn. 2 (1996).

3. L.C. Osuji and B.S. Antia, Appl. Sci. Environ. Manage., 9, 45 (2005).

4. B.P. Tissot and D.H. Welte, Petroleum Formation and Occurrence, Springer Verlag, Berlin, edn 2 (1984)

5. M. Asif, A. Nazir, T. Fazeelat, K. Grice, S. Nasir and A. Saleem, Petroleum Sci. Technol., 29, 2234 (2011).

6. I.B. Kadri, Petroleum Geology of Pakistan, Pakistan Petroleum Limited, Karachi (1995).

7. M. Blumer, Anal. Chem., 29, 1039 (1957).

8. R.A. Bourbonniere and P.A. Meyers, Limmol. Oceanogr., 41, 352 (1996).

9. A.D.O. Gomes and D.D.A. Azevedo, J. Braz. Chem. Soc., 14, 358 (2003).

10. W. Ahmed, S. Alam and S. Jahandad, Pak. J. Hydrocarbon Res., 14, 69 (2004).

11. K.E. Peters, C.C. Walters and J.M. Moldowan, The Biomarker Guide, Biomarkers and Isotopes in the Environment and Human History, Cambridge University Press, edn. 2 (2005).

12. R. Alexander, R.I. Kagi and G.W. Woodhouse, Am. Ass. Petrol. Geol. Bull., 65, 235 (1981).

13. J.E. Cooper and E.E. Bray, Geochim. Cosmochim. Acta, 27, 1113 (1963).

14. E. Gelpi, H. Schneider, J. Mann and J. Oro, Phytochemistry, 9, 603 (1970). 